\title{
BMJ Open Practices and attitudes of doctors and patients to downward referral in Shanghai, China
}

Wenya Yu, ${ }^{1}$ Meina $L i,{ }^{1}$ Xin Nong, ${ }^{2}$ Tao Ding, ${ }^{1}$ Feng Ye, ${ }^{1,3}$ Jiazhen Liu, ${ }^{1,4}$ Zhixing Dai, ${ }^{1}$ Lulu Zhang ${ }^{1}$

To cite: Yu W, Li M, Nong X, et al. Practices and attitudes of doctors and patients to downward referral in Shanghai, China. BMJ Open 2017;7:e012565 doi:10.1136/bmjopen-2016012565

- Prepublication history and additional material is available. To view please visit the journal (http://dx.doi.org/ 10.1136/bmjopen-2016012565).

WY, ML and XN contributed equally to this research.

Received 13 May 2016 Revised 6 March 2017 Accepted 7 March 2017

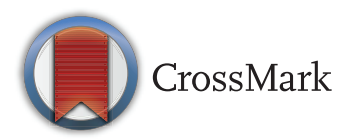

${ }^{1}$ Institute of Military Health Management, Second Military Medical University, Shanghai, China

${ }^{2}$ Maternal and Child Service Center of Rizhao City, Rizhao, China

${ }^{3}$ No 187th hospital of PLA, Haikou, China

${ }^{4}$ Shanghai Sixth People's Hospital, Shanghai, China

Correspondence to Professor Lulu Zhang; zllrmit@aliyun.com

\section{ABSTRACT}

Objectives: In China, the rate of downward referral is relatively low, as most people are unwilling to be referred from hospitals to community health systems (CHSs). The aim of this study was to explore the effect of doctors' and patients' practices and attitudes on their willingness for downward referral and the relationship between downward referral and sociodemographic characteristics.

Methods: Doctors and patients of 13 tertiary hospitals in Shanghai were stratified through random sampling. The questionnaire surveyed their sociodemographic characteristics, attitudes towards CHSs and hospitals, understanding of downward referral, recognition of the community first treatment system, and downward referral practices and willingness. Descriptive statistics, $\chi^{2}$ test and stepwise logistic regression analysis were employed for statistical analysis.

Results: Only 20.8\% (161/773) of doctors were willing to accept downward referrals, although this proportion was higher among patients (37.6\%, 326/ 866). Doctors' willingness was influenced by education, understanding of downward referral, and perception of health resources in hospitals. Patients' willingness was influenced by marital status, economic factors and recognition of the community first treatment system. Well-educated doctors who do not consider downward referral would increase their workloads and those with a more comprehensive understanding of hospitals and downward referral process were more likely to make a downward referral decision. Single-injury patients fully recognising the community first treatment system were more willing to accept downward referral. Patients' willingness was significantly increased if downward referral was costsaving. A better medical insurance system was another key factor for patients to accept downward referral decisions, especially for the floating population.

Conclusions: To increase the rate of downward referral, the Chinese government should optimise the current referral system and conduct universal publicity for downward referral. Doctors and patients should promote understandings of downward referral. Hospitals should realise the necessity of downward referral, effectively reduce workloads and provide continuing education for doctors. Increasing monetary reimbursement is urgent, as is improving the medical insurance system.

\section{Strengths and limitations of this study}

- Evaluating the practices and attitudes of the most important objects (doctors and patients) towards downward referral.

- Putting forward to some feasible and effective measures to promote doctors' and patients' willingness for downward referral, which can be implemented in short-term compared with other long-term policies.

- Bias in this study may result from a lack of some factors (eg, number of years doctors have worked in a hospital, type of disease, location of community health systems) and the comparison between different types of participants (eg, doctors from different healthcare institutions and with different working experience). The relation between geographical location and seriousness of diseases need to be explored since this study is set in an urban area.

\section{BACKGROUND}

The two-way referral system originated from the community first treatment system in the UK in 1948. Both systems were employed in many other developed countries. The two-way referral system includes referral from community health systems (CHSs) to hospitals (upward referral), mainly from general practitioners (GPs) to specialists for further diagnosis and treatment, and referral from hospitals to CHSs (downward referral), mainly from specialists to GPs for rehabilitation. ${ }^{1}$ In 1997, China proposed the Decision of the Communist Party of China (CPC) Central Committee and the State Council on Health Reform and Development to establish the community first treatment system and two-way referral system. However, over the past two decades, despite the merits of the two systems, implementation did not meet expectations, especially those for the referral system from hospitals to CHSs (downward referral system). The healthcare system in China is a three-level system, consisting of 
primary healthcare institutions (eg, CHSs and rural healthcare clinics), secondary hospitals (eg, county or district hospitals) and tertiary hospitals (eg, topmost hospitals). The referral system usually connects CHSs and tertiary hospitals. However, there is an imbalance on the amount of patients treated in CHSs and hospitals, as most patients prefer hospitals. Currently, people have the freedom to choose an ideal healthcare institution, and there are no strict constraints on community first treatment. Usually, patients prefer hospitals (especially topmost hospitals) to CHSs, because of the better healthcare provided they presume, unless doctors make downward referral decisions. This phenomenon has been demonstrated in several investigations. According to a survey published by the China National Development and Reform Commission in 2006, 41.4\% of respondents would not choose CHSs if they were ill, compared with only $28.6 \%$ who would choose CHSs (30.0\% without a clear preference) $;^{2}$ the number of upward and downward referrals accounted for $96.36 \%$ and $3.64 \%$ of the total number of referrals, respectively; ${ }^{3}$ and among all patients, $11.39 \%$ of them experienced referral, with $8.95 \%$ experienced upward referral, $2.44 \%$ experienced downward referral. ${ }^{4}$ Therefore, compared with the general referral rate of $20-30 \%$ released by the WHO, the referral rate in China is far from the international standard, especially for downward referrals. This phenomenon also indicated that the current situation in China was not reasonable; the WHO had suggested that $70-80 \%$ of diseases can be diagnosed and treated in CHSs, and patients should be referred from hospitals to CHSs for rehabilitation. ${ }^{3}$ In addition, considering downward referral can reduce medical costs by 8 $16 \%$, it should be encouraged to be implemented in China. ${ }^{5-9}$

Globally, there are many studies on the factors influencing referral. Given the perfection of the GP system and reasonable rate of downward referral in many developed countries, foreign studies concentrate more on factors influencing upward referral by focusing on five aspects -sociodemographic characteristics of patients, ${ }^{10-12}$ financial situation of patients, ${ }^{13}$ characteristics of healthcare institutions, ${ }^{14}$ characteristics of doctors ${ }^{13}{ }^{15-17}$ and their perceptions of referral, ${ }^{18}$ and medical insurance. ${ }^{12}$ However, a study in China showed that $93.4 \%$ of patients and their families are unwilling to be referred from hospitals to CHSs. ${ }^{19}$ Thus, more attention should be focused on downward referral. Three factors influence downward referral in China, namely insufficient effective downward referral policies, incomplete development of CHSs, and poor cognition of doctors and patients of downward referral.

Insufficient effective downward referral policies are one of the barriers to downward referral. In 2000, China proposed the development of GPs in the Guidelines for Urban Medical and Health Reform. In 2006, a pilot programme for the community first treatment system and downward referral system was put in place. Guided by the CPC Central Committee and State Council Opinions on Deepening Medical and Health System Reform, 2009 and 2012, a series of policies were implemented to determine the standards for two-way referral. Nevertheless, proposal and implementation of the downward referral system in China occurred 50 years later than in the UK, and current policies still do not include much information on unified and specific standards, processes, incentives, downward referral supervision, ${ }^{20-22}$ and reimbursement of medical insurance after patients are referred to CHSs. ${ }^{23-27}$

Unbalanced health resource allocation and relatively poor medical technology in CHSs (compared with hospitals) is another key factor impeding the implementation of downward referral. ${ }^{12} 2328{ }^{29}$ Although the development of CHSs is improving, current progress cannot completely balance health resource allocation and improve medical technology in CHSs, leaving much room for improvement. In 2012, the number of beds in hospitals $(4160000)$ was 20 times that in CHSs (203 200), the number of medical staff in hospitals (4 057 640) was 10.48 times that in CHSs (386 952) and the number of hospital outpatient visits $(2541000000)$ was 3.24 times that in CHSs (566 000000$).{ }^{30}$

The practices and attitudes of doctors and patients to referral can influence their willingness for downward referral. Studies indicated that doctors' poor understanding of referral from hospitals to CHSs was a key obstacle to downward referral. ${ }^{20} 233132$ Doctors' understanding of downward referral mostly depends on their clinical experience, skills and knowledge $;{ }^{33}{ }^{34}$ medical institutions' perception of economic benefits; ${ }^{23} 283132$ and doctors' perception of referral patterns. ${ }^{33}$ In addition, patients' attitudes towards downward referral played an important role in downward referral decisionmaking. Statistics suggest that $48.6 \%$ of doctors refused to make downward referrals, because of patients' unwillingness, while $53.6 \%$ of patients refused downward referral, because they did not sufficiently understand the referral system. ${ }^{35}$ Patients' attitudes towards downward referral is also influenced by their medical preference, ${ }^{4} 28313637$ medical information, ${ }^{23}$ patient-doctor communication, ${ }^{38}$ quality of referral services, ${ }^{39}$ course of diseases ${ }^{39}$ and sociodemographic characteristics (eg, age, residence). ${ }^{40} 41$

Considering the characteristics of policymaking and long-term development process of CHSs, it is impossible to thoroughly conduct the community first treatment system and downward referral system, and improve the development of CHSs in the short term. Given the flexibility of doctors' and patients' practices and attitudes towards referral, the low rate of downward referral and its advantage of reducing medical costs, ${ }^{42}$ this study focused on the practices and attitudes of doctors and patients to downward referral. Therefore, the aim of this study was to explore whether doctors' and patients' practices and attitudes to downward referral influence their willingness for referral from hospitals to CHSs, and the 
relationship between downward referral and sociodemographic characteristics.

\section{METHODS}

\section{Materials and methods}

The investigation was conducted from July to September 2013. Using random sampling, 13 tertiary hospitals in Shanghai were selected (all these hospitals were in an urban area), and questionnaires were randomly distributed to doctors and patients in these hospitals. Participants were selected through random number tables, which were based on doctors' job numbers, outpatients' registration numbers and inpatients' admission numbers. Before the formal investigation, 50 outpatients and 50 doctors (who were excluded from the main analysis) were recruited for a preliminary survey. Based on the results of the preliminary survey, some items were eliminated or revised. One item was eliminated from the questionnaire for patients because of a high nonresponse rate $(82.4 \%)$, and three items in the questionnaire for doctors were revised owing to the improper responses. These three items were doctors' attitudes towards healthcare service in CHSs, understandings of the process and standards for downward referral, which were rated on a five-point scale. However, the preliminary survey revealed that all participating doctors have only worked in hospitals and most of them were not familiar with CHSs and the downward referral system. This made it difficult to make an accurate selection from the options of the five-point scale. One study indicated that a three-point scale is more suitable than a fivepoint scale for people with intellectual disabilities or those not familiar with the surveyed issue. ${ }^{43}$ Therefore, based on the combined recommendations of participating doctors, existing literature and questionnaire design experts, we revised the three items as a three-point scale.

In the formal survey where 1000 doctors were approached, and 773 completed the questionnaire, doctors' response rate was $77.3 \%$. Furthermore, 866 of 1000 patients responded to the questionnaire to a total response rate of $86.6 \%$. All participants were selected at random from each hospital who voluntarily participated and had the ability to complete the questionnaire (only patients $\geq 18$ years old were included to ensure the quality of the survey). Before handing out the questionnaire, all participants gave their written informed consent, and their privacy was guaranteed to be protected. All investigators were trained professionally by experts and professors, and were responsible for explaining and clarifying unclear items to participants.

The survey on doctors investigated their sociodemographic characteristics, knowledge of healthcare services in CHSs, understanding of downward referral and perception of health resources in their hospitals. The questionnaire for doctors comprised 11 items (see online supplementary material 1) to describe their sociodemographic characteristics and attitudes to downward referral. The patient survey focused on sociodemographic characteristics, attitudes to healthcare service in CHSs, practice and understanding of downward referral, and recognition of the community first treatment system. The questionnaire for patients comprised 14 items (see online supplementary material 2). To demonstrate the reliability of the questionnaires, we determined internal consistency through Cronbach's $\alpha$ coefficient. Cronbach's $\alpha$ coefficient is one of the most universal indicators of reliability, and a Cronbach's $\alpha$ coefficient of $>0.7$ indicates that a questionnaire has good reliability. Furthermore, the validity of a questionnaire can be testified through content validity and factor analysis. Content validity suggests consistency between participants' understanding of the items and the original goals of questionnaire design. Generally, it is verified through expert assessment; therefore, we invited five experts to assess content validity. We also conducted an explorative factor analysis to further assess validity using the Kaiser-Meyer-Olkin (KMO) test and varimax rotation method. If $\mathrm{KMO}>0.7$, good validity of the questionnaire is indicated.

Data were entered by two authors simultaneously using the software Epidata V.3.1. Data analyses were conducted using SAS V.8.0 and SPSS V.18.0. Descriptive statistics were used to describe the sociodemographic characteristics of doctors and patients, and a $\chi^{2}$ test was employed to analyse the willingness of doctors and patients for downward referral. Stepwise logistic regression analysis was employed to analyse the relation between willingness for downward referral and sociodemographic characteristics, as well as the relation between willingness for downward referral and practices and attitudes towards downward referral. All tests were two-way, and $\mathrm{p}<0.05$ was considered statistically significant.

\section{Ethics statement}

Only doctors and patients who provided their written informed consent were enrolled in the study. All participants were explicitly aware of the aims and objectives of the study, and were informed that participation was voluntary and confidentiality would be protected.

\section{RESULTS}

\section{Reliability and validity of the questionnaire}

According to the reliability test, Cronbach's $\alpha$ coefficient for the questionnaire for doctors and patients were 0.707 and 0.711 , respectively. The test for the two questionnaires indicated good reliability for both. In addition, five experts evaluated the two questionnaires as having good content validity, meaning good consistency between participants' understanding of the items and the original goals of questionnaire design. Based on the $\mathrm{KMO}$ test, the KMO coefficient for the doctors' questionnaire was 0.706 , and the $\mathrm{p}$ value of Bartlett's Test of Sphericity was $\mathrm{p}<0.001$. The KMO coefficient for the 
patients' questionnaire was 0.702 , and the $\mathrm{p}$ value of Bartlett's Test of Sphericity was $\mathrm{p}<0.001$. The results of the KMO test suggest that the two questionnaires have good validity.

\section{Sociodemographic characteristics of doctors and patients Sociodemographic characteristics of doctors}

Sociodemographic characteristics of doctors include gender, age, level of education, title and department are shown in the table (table 1). Of the 773 participating doctors, $55.6 \%$ were men and $44.4 \%$ were women. All were aged 20-60 years, and most of them were 3039 years old. Most doctors were well educated: $71.7 \%$ had obtained a master's or doctor's degree. Most participants were doctors with an intermediate professional title $(42.2 \%)$, and only $6.6 \%$ of senior doctors were enrolled in the study. The doctors considered were mainly from the internal medicine department $(42.7 \%)$ and surgery department $(37.9 \%)$.

\section{Sociodemographic characteristics of patients}

Sociodemographic characteristics of patients include gender, occupation, age, average monthly income, marital status, level of education, annual medical expenses and medical insurance are shown in the table (table 2). Among the 866 participating patients, 46.9\% were men and $53.1 \%$ were women. Apart from other occupations $(24.1 \%), 21.4 \%$ of the participants were retirees, followed by students, workers and medical staff. Most participants were young adults aged between 20 and 40 years $(53.1 \%$ ), followed by the elderly (age $\geq 60$; $17.4 \%)$. Most patients (53.3\%) were from the lowincome and medium-income population, with an average monthly income of 2000-5000 renminbi (RMB; $\sim$ US\$308-US\$770). Most of the patients were married $(67.7 \%)$. Except for a relatively small proportion of participating patients with primary degrees (only 5.4\%), there was not a great gap among those with other levels of education. Only a few patients spent more than RMB10 000 annually on medicine, and most of them spent $<$ RMB1000 every year. Furthermore, $92.4 \%$ of patients had at least one type of medical insurance.

\section{Influencing factors of doctors' and patients' willingness for downward referral}

In this section, $\chi^{2}$ tests were employed to test the relationship between doctors' and patients' willingness for downward referral and their sociodemographic characteristics, as well as their practices and attitudes towards downward referral. The actual frequency, theoretical frequency, $\chi^{2}$ value and $p$ value of various factors are provided in tables 1 and 2 .

\section{Factors influencing doctors' willingness to make downward referrals}

Level of education ( $p=0.002)$, understanding of the downward referral process $(p=0.018)$, perception of the limitations of health resources in hospitals $(p<0.0001)$ and attitudes towards workloads $(\mathrm{p}<0.0001)$ affected by downward referral were related to doctors' willingness to make downward referrals. Other sociodemographic characteristics and doctors' attitudes to other issues (all $\mathrm{p}>0.05$ ) were not statistically significant regarding their willingness to make downward referrals (table 1).

Though most sociodemographic characteristics were not statistically significant regarding doctors' willingness to make downward referrals, variations between categories were found. Among 773 doctors, only $20.8 \%$ were willing to refer patients from hospitals to the CHS. Of male doctors, $20.5 \%$ were willing to refer patients to CHSs, and $21.3 \%$ of female doctors. Furthermore, $24.5 \%$ of doctors aged 20-29 accepted downward referral, and $21.0 \%, 17.0 \%$ and $22.9 \%$ for those aged $30-39$, 40-49 and 50-59, respectively. The proportions of doctors with junior, intermediate, associate senior and senior professional titles were $24.0 \%, 20.9 \%, 17.3 \%$ and $13.7 \%$, respectively. In other departments, $23.2 \%$ of doctors were willing to refer patients to CHSs, $21.8 \%$ doctors in the medical technology department, $20.0 \%$ physicians and $20.8 \%$ surgeons.

\section{Factors influencing patients' willingness for downward referral}

Sociodemographic characteristics (all $\mathrm{p}>0.05$ ) were not associated with patients' willingness for downward referral. Only the degree of patients' recognition of the community first treatment system $(p=0.001)$ and whether downward referral could save medical costs $(p<0.0001)$ were statistically significant to their willingness for downward referral (table 2).

There were $37.6 \%$ patients $(326 / 866)$ who accepted downward referral, but sociodemographic characteristics did not influence their willingness for downward referral. Among male patients, $37.2 \%$ willing to be referred downward and only $38.0 \%$ of female patients. For patients with different occupations, the ratios were $33.3 \%$ for medical staff, $29.4 \%$ for civil servants, $37.3 \%$ for retirees, $43.0 \%$ for farmers, $35.9 \%$ for workers and $34.1 \%$ for students. Furthermore, $37.9 \%$ of younger patients ( $<60$ years) accepted downward referral, while $36.4 \%$ of older patients ( $\geq 60$ years) preferred to be referred to CHSs. Of the lower income patients $(<$ RMB8000), $38.0 \%$ were willing to be referred to CHSs, and only $31.4 \%$ of higher income patients $(\geq$ RMB8000) were willing. In total, $39.5 \%, 39.6 \%$ and $32.6 \%$ of divorced/widowed, married and single patients were willing to be referred to CHSs, respectively. Of patients with a lower level of education (below a bachelor's degree), $38.2 \%$ accepted downward referral, as did $36.4 \%$ of higher educated patients (a bachelor's degree and higher). There were $37.5 \%$ and $39.2 \%$ patients with lower $(<$ RMB10 000) and higher $(\geq$ RMB10 000) annual medical expenses who accepted downward referral. Patients preferring downward referral accounted for $27.3 \%$ of those with medical insurance, and $38.5 \%$ of those without. 
Table 1 Doctors' sociodemographic characteristics and practices and attitudes towards downward referral

\begin{tabular}{|c|c|c|c|c|c|}
\hline \multirow[b]{2}{*}{ Category } & \multirow[b]{2}{*}{$\mathbf{N}(\%)$} & \multicolumn{2}{|c|}{$\begin{array}{l}\text { Willingness of downward } \\
\text { referral }\end{array}$} & \multirow[b]{2}{*}{$\chi^{2} \ddagger$} & \multirow[b]{2}{*}{ p Value§ } \\
\hline & & Yes $\left(A^{*}, T \dagger\right)$ & No $\left(A^{*}, T+\right)$ & & \\
\hline \multicolumn{6}{|c|}{ Part I: sociodemographic characteristics } \\
\hline \multicolumn{4}{|l|}{ Gender } & 0.077 & 0.781 \\
\hline Male & $430(55.6)$ & $88(89.6)$ & $342(340.4)$ & & \\
\hline Female & $343(44.4)$ & $73(71.4)$ & $270(271.6)$ & & \\
\hline \multicolumn{4}{|l|}{ Age } & 2.836 & 0.418 \\
\hline $20-29$ & $139(18.0)$ & $34(29.0)$ & $105(110.1)$ & & \\
\hline 30-39 & 404 (52.3) & $85(84.1)$ & 319 (319.9) & & \\
\hline $40-49$ & $182(23.5)$ & $31(37.9)$ & $151(144.1)$ & & \\
\hline $50-59$ & $48(6.2)$ & $11(10.0)$ & $37(38.0)$ & & \\
\hline \multicolumn{4}{|l|}{ Level of education } & 14.905 & 0.002 \\
\hline Junior college degree & $7(0.9)$ & $3(1.5)$ & $4(5.5)$ & & \\
\hline Bachelor's degree & $211(27.3)$ & $57(43.9)$ & 154 (167.1) & & \\
\hline Master's degree & $352(45.5)$ & 75 (73.3) & 277 (278.7) & & \\
\hline Doctor's degree & 203 (26.3) & 26 (42.3) & 177 (160.7) & & \\
\hline \multicolumn{4}{|l|}{ Professional title } & 4.122 & 0.249 \\
\hline Junior and others & $263(34.0)$ & $63(54.8)$ & 200 (208.2) & & \\
\hline Intermediate & 326 (42.2) & 68 (67.9) & $258(258.1)$ & & \\
\hline Associate senior & 133 (17.2) & $23(27.7)$ & 110 (105.3) & & \\
\hline Senior & $51(6.6)$ & 7 (10.6) & $44(40.4)$ & & \\
\hline \multicolumn{4}{|l|}{ Department } & 0.482 & 0.923 \\
\hline Others & 95 (12.3) & $22(19.8)$ & 73 (75.2) & & \\
\hline Medical technology & $55(7.1)$ & $12(11.5)$ & $43(43.5)$ & & \\
\hline Internal medicine & $330(42.7)$ & $66(68.7)$ & $264(261.3)$ & & \\
\hline Surgery & $293(37.9)$ & $61(61.0)$ & 232 (232.0) & & \\
\hline \multicolumn{6}{|c|}{ Part II: practices and attitudes towards downward referral } \\
\hline \multicolumn{4}{|c|}{ Knowledge of healthcare services provided by $\mathrm{CHSs}$} & 3.063 & 0.216 \\
\hline Know nothing & $347(44.9)$ & $71(72.3)$ & $276(274.7)$ & & \\
\hline Partly know & $305(39.5)$ & $71(63.5)$ & $234(241.5)$ & & \\
\hline Fully understand & $121(15.7)$ & $19(25.2)$ & $102(95.8)$ & & \\
\hline \multicolumn{4}{|c|}{ Knowledge of downward referral process } & 8.016 & 0.018 \\
\hline Know nothing & $364(47.1)$ & $80(75.8)$ & $284(288.2)$ & & \\
\hline Partly know & $275(35.6)$ & $65(57.3)$ & $210(217.7)$ & & \\
\hline Fully understand & $134(17.3)$ & $16(27.9)$ & $118(106.1)$ & & \\
\hline \multicolumn{4}{|c|}{ Knowledge of downward referral standards } & 0.788 & 0.674 \\
\hline Know nothing & $366(47.3)$ & $75(76.1)$ & $291(289.8)$ & & \\
\hline Partly know & $273(35.3)$ & $61(56.9)$ & $212(216.1)$ & & \\
\hline Fully understand & $134(17.3)$ & $25(27.9)$ & $109(106.1)$ & & \\
\hline \multicolumn{4}{|c|}{ Understanding of the limitations of health resources in hospitals } & 25.341 & $<0.0001$ \\
\hline Cannot understand & $15(1.9)$ & $10(3.1)$ & $5(11.9)$ & & \\
\hline Understand a little & $47(6.1)$ & $10(9.8)$ & $37(37.2)$ & & \\
\hline Moderate & $230(29.8)$ & 49 (47.9) & $181(182.1)$ & & \\
\hline Partly understand & $268(34.7)$ & $41(55.8)$ & $227(212.2)$ & & \\
\hline Fully understand & $213(27.6)$ & $51(44.4)$ & 162 (168.6) & & \\
\hline \multicolumn{4}{|c|}{ Attitudes towards workloads affected by downward referralq } & 22.247 & $<0.0001$ \\
\hline Does not increase workloads & $481(62.2)$ & $126(100.2)$ & $355(380.8)$ & & \\
\hline Increase workloads & $292(37.8)$ & $35(60.8)$ & $257(231.2)$ & & \\
\hline \multicolumn{6}{|c|}{$\begin{array}{l}\text { *A is the actual frequency in } \chi^{2} \text { test. } \\
\dagger T \text { is the theoretical frequency in } \chi^{2} \text { test. } \\
\text { tThe } \chi^{2} \text { is the test statistic of } \chi^{2} \text { test. } \\
\text { \$p Value<0.05 is considered statistically significant. } \\
\text { १The judgement on different aspects of doctors' attitudes towards downward referral was determined according to the degree (from the most } \\
\text { negative option to the most positive option) of doctors' knowledge, understanding and perception. } \\
\text { CHS, community health system. }\end{array}$} \\
\hline
\end{tabular}


Table 2 Patients' sociodemographic characteristics and practices and attitudes towards downward referral

\begin{tabular}{|c|c|c|c|c|c|}
\hline \multirow[b]{2}{*}{ Category } & \multirow[b]{2}{*}{$\mathbf{N}(\%)$} & \multicolumn{2}{|c|}{$\begin{array}{l}\text { Willingness of downward } \\
\text { referral }\end{array}$} & \multirow[b]{2}{*}{$\chi^{2} \ddagger$} & \multirow[b]{2}{*}{ p Value§ } \\
\hline & & Yes $\left(A^{*}, T+\right)$ & No $\left(A^{*}, T+\right)$ & & \\
\hline \multicolumn{6}{|l|}{ Part I: sociodemographic characteristics } \\
\hline Gender & & & & 0.067 & 0.796 \\
\hline Male & $406(46.9)$ & $151(152.8)$ & 255 (253.2) & & \\
\hline Female & $460(53.1)$ & 175 (173.2) & $285(286.8)$ & & \\
\hline Occupation & & & & 5.779 & 0.448 \\
\hline Others & $209(24.1)$ & $89(78.7)$ & 120 (130.3) & & \\
\hline Medical staff & 93 (10.7) & $31(35.0)$ & $62(58.0)$ & & \\
\hline Civil servant & $34(3.9)$ & $10(12.8)$ & $24(21.2)$ & & \\
\hline Retiree & $185(21.4)$ & 69 (69.6) & $116(115.4)$ & & \\
\hline Farmer & $79(9.1)$ & $34(29.7)$ & $45(49.3)$ & & \\
\hline Workerף & $131(15.1)$ & 47 (49.3) & $84(81.7)$ & & \\
\hline Student & $135(15.5)$ & $46(50.8)$ & 89 (84.2) & & \\
\hline Age (year) & & & & 3.570 & 0.613 \\
\hline$<20$ & 37 (4.3) & $12(13.9)$ & $25(23.1)$ & & \\
\hline 20-29 & $292(33.7)$ & $104(109.9)$ & $188(182.1)$ & & \\
\hline 30-39 & $168(19.4)$ & 73 (63.2) & 95 (104.8) & & \\
\hline $40-49$ & 103 (11.9) & $40(38.8)$ & $63(64.2)$ & & \\
\hline $50-59$ & 115 (13.3) & 42 (43.3) & $73(71.7)$ & & \\
\hline$\geq 60$ & $151(17.4)$ & $55(56.8)$ & $96(94.2)$ & & \\
\hline \multicolumn{2}{|l|}{ Average monthly income (RMB) } & & & 2.709 & 0.608 \\
\hline$<2000$ & $273(31.5)$ & $104(102.8)$ & 169 (170.2) & & \\
\hline 2000-2999 & 250 (28.9) & $94(94.1)$ & $156(155.9)$ & & \\
\hline $3000-4999$ & $211(24.4)$ & $76(79.4)$ & 135 (131.6) & & \\
\hline $5000-7999$ & $81(9.4)$ & $36(30.5)$ & $45(50.5)$ & & \\
\hline$\geq 8000$ & $51(5.9)$ & $16(19.2)$ & $35(31.8)$ & & \\
\hline \multicolumn{2}{|l|}{ Marital status } & & & 3.573 & 0.168 \\
\hline Divorced/widowed & $38(4.4)$ & $15(14.3)$ & $23(23.7)$ & & \\
\hline Married & $586(67.7)$ & $232(220.6)$ & $354(365.4)$ & & \\
\hline Single & $242(27.9)$ & $79(91.1)$ & 163 (150.9) & & \\
\hline \multicolumn{2}{|l|}{ Level of education } & & & 2.209 & 0.697 \\
\hline Primary degree and below & $47(5.4)$ & $22(17.7)$ & $25(29.3)$ & & \\
\hline Junior high school degree & $191(22.1)$ & 71 (71.9) & $120(119.1)$ & & \\
\hline Senior school degree & $179(20.7)$ & $70(67.4)$ & 109 (111.6) & & \\
\hline Junior college degree & $180(20.8)$ & $65(67.8)$ & 115 (112.2) & & \\
\hline Bachelor's degree and above & $269(31.1)$ & 98 (101.3) & $171(167.7)$ & & \\
\hline \multicolumn{2}{|l|}{ Annual medical expense (RMB) } & & & 2.305 & 0.512 \\
\hline$<1000$ & $387(44.7)$ & $150(145.7)$ & 237 (241.3) & & \\
\hline $1000-4999$ & $339(39.1)$ & $129(127.6)$ & $210(211.4)$ & & \\
\hline 5000-9999 & 89 (10.3) & $27(33.5)$ & $62(55.5)$ & & \\
\hline$\geq 10000$ & $51(5.9)$ & $20(19.2)$ & $31(31.8)$ & & \\
\hline \multicolumn{2}{|l|}{ Medical insurance** } & & & 3.274 & 0.070 \\
\hline No & $66(7.6)$ & $18(24.8)$ & $48(41.2)$ & & \\
\hline Yes & $800(92.4)$ & $308(301.2)$ & $492(498.8)$ & & \\
\hline \multicolumn{6}{|c|}{ Part II: practices and attitudes towards downward referral } \\
\hline \multicolumn{4}{|l|}{ Experience of downward referral } & 0.147 & 0.701 \\
\hline No & $793(91.6)$ & $297(298.5)$ & $496(494.5)$ & & \\
\hline Yes & $73(8.4)$ & $29(27.5)$ & $44(45.5)$ & & \\
\hline \multicolumn{4}{|c|}{ Degree of medical demand met by healthcare services provided by $\mathrm{CHSs \dagger \dagger}$} & 8.112 & 0.088 \\
\hline Completely unable to be met & $59(6.8)$ & $24(22.2)$ & $35(36.8)$ & & \\
\hline Can be met a little & $220(25.4)$ & $98(82.8)$ & $122(137.2)$ & & \\
\hline Moderate & 479 (55.3) & $162(180.3)$ & $317(298.7)$ & & \\
\hline Can partly be met & $98(11.3)$ & 39 (36.9) & $59(61.1)$ & & \\
\hline Can completely be met & $10(1.2)$ & $3(3.8)$ & $7(6.2)$ & & \\
\hline \multicolumn{4}{|l|}{ Degree of satisfaction with $\mathrm{CHSs} \dagger+$} & 5.368 & 0.252 \\
\hline Completely dissatisfied & $39(4.5)$ & $13(14.7)$ & $26(24.3)$ & & \\
\hline Mostly dissatisfied & $123(14.2)$ & 57 (46.3) & $66(76.7)$ & & \\
\hline
\end{tabular}




\begin{tabular}{|c|c|c|c|c|c|}
\hline \multirow[b]{2}{*}{ Category } & \multirow[b]{2}{*}{$\mathbf{N}(\%)$} & \multicolumn{2}{|c|}{$\begin{array}{l}\text { Willingness of downward } \\
\text { referral }\end{array}$} & \multirow[b]{2}{*}{$\chi^{2} \ddagger$} & \multirow[b]{2}{*}{ p Value§ } \\
\hline & & Yes $\left(A^{*}, T \dagger\right)$ & No $\left(A^{*}, T \dagger\right)$ & & \\
\hline Moderate & $530(61.2)$ & $193(199.5)$ & $337(330.5)$ & & \\
\hline Mostly satisfied & $156(18.0)$ & $58(58.7)$ & $98(97.3)$ & & \\
\hline Completely satisfied & $18(2.1)$ & $5(6.8)$ & $13(11.2)$ & & \\
\hline \multicolumn{3}{|c|}{ Recognition of the community first treatment system $† \dagger$} & & 19.541 & 0.001 \\
\hline Cannot recognise & $44(5.1)$ & $19(16.6)$ & $25(27.4)$ & & \\
\hline Recognise a little & $132(15.2)$ & $67(49.7)$ & $65(82.3)$ & & \\
\hline Moderate & $515(59.5)$ & $193(193.9)$ & $322(321.1)$ & & \\
\hline Partly recognise & $155(17.9)$ & $40(58.3)$ & $115(96.7)$ & & \\
\hline Completely recognise & $20(2.3)$ & $7(7.5)$ & $13(12.5)$ & & \\
\hline \multicolumn{3}{|c|}{ Cost-saving because of downward referral $\dagger \dagger$} & & 32.169 & 0.000 \\
\hline No & $673(77.7)$ & $287(253.3)$ & $386(419.7)$ & & \\
\hline Yes & $193(22.3)$ & $39(72.7)$ & $154(120.3)$ & & \\
\hline \multicolumn{6}{|c|}{$\begin{array}{l}{ }^{*} \mathrm{~A} \text { is the actual frequency in } \chi^{2} \text { test. } \\
\dagger \mathrm{T} \text { is the theoretical frequency in } \chi^{2} \text { test. } \\
\text { †The } \chi^{2} \text { is the test statistic of } \chi^{2} \text { test. } \\
\S p \text { Value }<0.05 \text { is considered statistically significant. } \\
\text { ПWorkers are the population working in factories and enterprises. } \\
{ }_{\star}^{*} \text { Medical insurance includes the three basic types of medical insurance in China (Urban Employees' Basic Medical Insurance System, Urban } \\
\text { Residents' Basic Medical Insurance System, New Rural Co-operative Medical Care System) and private health insurance. } \\
\text { ††The judgement on different aspects of patients' attitudes towards downward referral was determined according to the degree (from the most } \\
\text { negative option to the most positive option) of patients' knowledge, understanding and perception. } \\
\text { CHS, community health system; RMB, renminbi. }\end{array}$} \\
\hline
\end{tabular}

\section{Logistic regression analysis of doctors' and patients'} willingness for downward referral

In this test, stepwise logistic regression analysis was used to explore factors influencing doctors' and patients' willingness for downward referral. Based on the $\chi^{2}$ test, variables statistically significant to the willingness for downward referral were selected for the logistic regression equation (table 3 ).

\section{Logistic regression analysis of doctors' willingness to make downward referrals}

Three factors (attitude towards workload affected by downward referral, perception of the limitations of health resources in hospitals and level of education) were included in the analysis for doctors' willingness to make downward referrals. According to the OR, it was more likely for doctors to accept downward referral if they do not think the practice of downward referral would not increase their workload. Compared with those who realised the limitations of health resources in hospitals, doctors who understood nothing were less likely to support downward referral. In addition, doctors who are better educated were more likely to refer patients downward (table 3).

\section{Logistic regression analysis of patients' willingness for downward referral}

Patients' marital status, having medical insurance, considered downward referral a cost-saving choice and being aware of the community first treatment system were selected for the logistic regression equation. Patients who regard downward referral as a cost-saving choice were more likely to choose downward referral. Although recognising the community first treatment system was related to patients' willingness for downward referral, the degree of recognition was not statistically significant. Moreover, the marital status of patients was associated with willingness for downward referral, and married patients were less likely to accept downward referral than single patients. However, whether patients had medical insurance was not statistically significant (table 3).

\section{DISCUSSION}

Based on the statistical analysis, doctors' attitudes towards workload, perception of health resources in hospitals, understanding of the downward referral process and level of education were key factors influencing their willingness for downward referral. Patients' willingness for downward referral was mainly influenced by economic factors, marital status and recognition of the community first treatment system.

\section{Doctors' willingness to make downward referrals}

Doctors who are better educated were more likely to accept downward referral. ${ }^{44}$ To better understand this point, we briefly introduce the medical degree system in China. This system awards bachelor's degrees, master's degrees (Master of Medicine (MM) and Master of Clinical Medicine (MCM)) and doctorate degrees (Doctor of Medicine (DM) and Doctor of Clinical Medicine (DCM)). Doctors with MM or DM degrees are physician scientists, with primary task of medical 
Table 3 Logistic regression analysis of downward referral

\begin{tabular}{|c|c|c|c|c|c|}
\hline \multirow[b]{2}{*}{ Parameter } & \multirow[b]{2}{*}{ Estimate* } & \multirow[b]{2}{*}{ p Valuet } & \multirow[b]{2}{*}{ OR‡ } & \multicolumn{2}{|c|}{ 95\% Wald Cl§ } \\
\hline & & & & Lower limit & Upper limit \\
\hline \multicolumn{6}{|c|}{ Part I: logistic regression analysis of doctors' willingness of downward referral } \\
\hline Attitudes towards workload affected by downward referral & 0.963 & $<0.0001$ & 2.620 & 1.725 & 3.979 \\
\hline \multicolumn{6}{|c|}{ Understanding of the limitations of health resources in hospitals } \\
\hline Cannot understand & -1.471 & 0.012 & 0.230 & 0.073 & 0.725 \\
\hline Understand a little & 0.306 & 0.449 & 1.358 & 0.615 & 2.997 \\
\hline Moderate & 0.326 & 0.167 & 1.385 & 0.872 & 2.201 \\
\hline Partly understand & 0.691 & 0.004 & 1.996 & 1.244 & 3.203 \\
\hline Fully understand & ref & ref & ref & ref & ref \\
\hline \multicolumn{6}{|l|}{ Level of education } \\
\hline Junior college degree & -1.353 & 0.114 & 0.258 & 0.048 & 1.381 \\
\hline Bachelor's degree & -1.018 & 0.0002 & 0.361 & 0.213 & 0.614 \\
\hline Master's degree & -0.605 & 0.017 & 0.546 & 0.332 & 0.899 \\
\hline Doctor's degree & ref & ref & ref & ref & ref \\
\hline \multicolumn{6}{|c|}{ Part II: logistic regression analysis of patients' willingness of downward referral } \\
\hline Cost-saving of downward referral & 1.090 & $<0.0001$ & 2.976 & 2.011 & 4.402 \\
\hline \multicolumn{6}{|l|}{ Recognition of the community first treatment system } \\
\hline Cannot recognise & -0.232 & 0.691 & 0.793 & 0.254 & 2.479 \\
\hline Recognise a little & -0.413 & 0.428 & 0.662 & 0.239 & 1.836 \\
\hline Moderate & 0.123 & 0.804 & 1.131 & 0.427 & 2.999 \\
\hline Partly recognise & 0.628 & 0.229 & 1.874 & 0.673 & 5.214 \\
\hline Completely recognise & ref & ref & ref & ref & ref \\
\hline \multicolumn{6}{|l|}{ Marital status } \\
\hline Divorced/widowed & -0.452 & 0.228 & 0.636 & 0.305 & 1.326 \\
\hline Married & -0.393 & 0.020 & 0.675 & 0.485 & 0.940 \\
\hline Single & ref & ref & & ref & ref \\
\hline Medical insurance & -0.494 & 0.096 & 0.610 & 0.340 & 1.097 \\
\hline \multicolumn{6}{|c|}{$\begin{array}{l}\text { *Estimate is the regression coefficient. } \\
\text { tp Value<0.05 is considered statistically significant. } \\
\text { †OR is a frequently used indicator for measuring the effect of independent variable on the response variable. } \\
\text { §Ninety-five per cent Wald } \mathrm{Cl} \text { is a range of interval estimation for OR, and the confidence level is determined as } 95 \% \text {. The } \mathrm{Cl} \text { for OR is a } \\
\text { range limited by the confidence limit, of which, the minimal value is called lower limit, and the maximal value is called upper limit. }\end{array}$} \\
\hline
\end{tabular}

research; those with MCM or DCM degrees emphasise clinical skills and work. ${ }^{45}$ In addition, this system is associated with but different from the Chinese physicians' professional title system, which evaluates the professional skills and abilities of physicians through awarding professional titles. Titles include junior (eg, feldsher, resident), intermediate (eg, physician), associate senior (eg, associate chief physician) and senior titles (eg, chief physician). The promotion of professional titles is partly influenced by physicians' medical degrees. ${ }^{46}$

Having a more comprehensive understanding of the Chinese medical degree system and professional title system enables a better understanding of the results of this study. As known, well-educated doctors were more likely to keep pace with medical policies (especially for $\mathrm{MM}$ and DM), which enables them to better understand the downward referral system and community first treatment system. They also have more opportunities to discover problems in their practices, such as unbalanced health resource allocation, unreasonable patient flow and the necessity of referring patients to lower level health institutions. Both aspects help well-educated doctors make appropriate decisions regarding downward referral. ${ }^{47}$ Therefore, it is indicated that providing more opportunities for continuing education may be a positive approach to improving the level of education of doctors in China, which will decrease the gap between the upward and downward referral rate. However, there are potential factors influencing this result according to expert consultations. In fact, doctors receiving more education in China are more likely to be entitled to senior titles, meaning they are often responsible for making decisions regarding referrals, which is why these doctors account for the highest proportion of those willing to refer patients to CHSs. In addition, some older clinical doctors do not have a high degree of education (usually referring to master's and doctorate degrees) in China; they are more adjusted to a nonreferral system. While younger doctors with a higher degree of education are more willing to receive more clinical referral information and guidelines, they are more confident in judging whether patients are suitable for downward referral. ${ }^{4}$ This helps them to determine the ideal time for making a downward referral decision. ${ }^{48}$ No matter the reasons behind this phenomenon, giving more chances for doctors to help improve their understanding of downward referral is a good option for increasing the possibility of downward referral. Some 
previous studies have proposed and proven this solution. For example, understanding more about a unified process of downward referral was a positive practice. $^{49} 50$ A regional medical association in Shanghai (China) discovered that a better understanding of the downward referral process increased doctors' willingness for downward referral. ${ }^{51}$ Another hospital in Shenzhen (China) successfully optimised the downward referral process, which promoted the rate of downward referral and improved patients' satisfaction. ${ }^{52}$ The attitude towards workload affected by downward referral was key to doctors' willingness for downward referral. Studies proved that doctors' perception of workload was a core factor influencing their decisions regarding referral. ${ }^{18}$ Doctors with heavier workloads were more dissatisfied with their jobs and lacked enthusiasm for their work. ${ }^{53}$ Moreover, the greatest obstacle for downward referral in China was disagreement of patients and their families; ${ }^{19}$ therefore, doctors have to spend more time on patientdoctor communication to make a downward referral decision. Unfortunately, the increased work time due to more frequent and time-consuming communication increased doctors' workloads, which ultimately reduced their willingness to make downward referrals. Based on this, measures should be taken to deal with the contradiction. Aside from reducing doctors' workloads, it is feasible for hospitals to establish a working group responsible for communication with patients and their families. For communities and residents, educational information on the reasonableness and merits of downward referral is a good solution. For the government, policies promoting people's willingness for downward referral and adjusting doctors' current working conditions should also be considered.

Doctors with a comprehensive perception of the limitations of health resources in hospitals were more willing to refer patients to CHSs. The reality in China is that patients afflicted with common or minor diseases prefer hospitals and specialists to CHSs. They occupy highquality health resources that should be provided to acute and severe patients in hospitals. Further, to ensure the health services for common or minor diseases in CHSs, the government has increased the input of health resources in CHSs in recent years. Although the amount is not as sufficient as hospitals, these resources are still wasted because patients still prefer hospitals to CHSs. ${ }^{54-56}$ Therefore, if doctors realise this reality and better understand the shortage of health resources in hospitals, they will be more willing to refer patients to CHSs. Moreover, doctors will better understand health resources in hospitals if they acknowledged the benefits of downward referral, such as decreasing the medical costs of patients, ${ }^{57} 58$ a higher bed turnover rate in hospitals, and shorter average hospitalisation days. ${ }^{21}$ However, it must be pointed out that hospitals in China sometimes refuse to refer patients to CHSs for their own monetary profit, which precludes downward referral to some extent. ${ }^{59} 60$ Therefore, in conclusion, continuing education for doctors to help them realise the scarcity and waste of health resources in hospitals is important. Hospitals should accelerate the implementation of downward referral, regardless of monetary profit, and this determination can be assured by punitive policies formulated by the Chinese government.

\section{Patients' willingness for downward referral}

Economic factors play a significant role in patients' willingness for downward referral. On the one hand, patients who consider downward referral as a cost-saving option were more willing to accept it. This result is understandable, because many patients in China prioritise economic factors when seeking medical treatment. In 2012, the average outpatient medical cost in tertiary hospitals (US\$35.1) was 2.86 times that in CHSs (US $\$ 12.3$ ), and the average inpatient medical cost in tertiary hospitals (US\$1621.3) was 4.63 times that in CHSs (US $\$ 350.4) .{ }^{30}$ Given the gap in medical costs between hospitals and CHSs, patients who are more sensitive to economic factors are more likely to choose a cheaper option if downward referral is feasible and healthcare services provided in CHSs are as good as those in hospitals. Paradoxically, even if the medical cost in CHSs was much lower than in hospitals, many patients facing financial problems refuse downward referral. The reason is the poor conditions in CHSs. Currently, there is a major shortage of GPs in CHSs, and the low quality of GPs is a problem. ${ }^{61}$ The WHO recommends 1 GP for every 2000 individuals. By the end of 2014, compared with 1 GP per 1500 individuals in the UK, 1.6 GP per 1000 individuals in France, 1 GP per 1500 individuals in the USA and 1.4 GP per 1500 individuals in Australia, there was only 1 GP per 120000 people in China. ${ }^{62}$ In addition, the low level of GPs' knowledge and skills impeded the implementation of downward referral. Patients refuse to be referred to CHSs, because they distrust the qualification of GPs in CHSs. Worse, doctors with better education or higher professional titles prefer to work in hospitals, which offer a respectable income and more opportunities for promotion. ${ }^{59}$ Therefore, under the premise of cheap healthcare services in CHSs, to encourage downward referral, effective measures should be taken to improve the quality of CHSs. Training more qualified GPs and increasing government health investment in CHSs may be the most powerful solution. ${ }^{63}$

On the other hand, medical insurance is a significant factor influencing downward referral. Although the importance of medical insurance in accelerating downward referral has been fully realised, ${ }^{64}$ the actual effect is far from satisfactory. First, the gap in reimbursement of medical insurance between hospitals and CHSs is not apparent enough to attract patients to CHSs. ${ }^{22}{ }^{27}$ Moreover, the complicated and indeterminate reimbursement process after being referred to CHSs impedes the completion of downward referral. ${ }^{26}$ The negative influence is particularly evident among floating 
populations. In China, many patients (especially those with critical and emergent diseases) seek medical treatment in well-developed cities (eg, Beijing and Shanghai). However, the current medical insurance system can hardly support reimbursement for patients floating into other areas (not in local areas where they participate in medical insurance). ${ }^{60}$ This non-universal medical insurance system makes it difficult to refer patients from hospitals to local CHSs. The small proportion of reimbursement and extremely complicated process mean that these people abandon low-level reimbursement and downward referral. Moreover, consequent to the rapid development of the economy and urbanisation in China, many young adults migrate from rural to urban areas for work. ${ }^{60}$ Most of this population was engaged in the New Rural Co-operative Medical Care System (NRCMCS) in local areas, ${ }^{65}$ but are no longer entitled to with urban residency status. Since the NRCMCS only supports reimbursement in local areas, which excludes the floating population, ${ }^{66}$ they must pay their own medical expenses. Considering they face heavy financial burdens, they prefer to go home rather than be referred to CHSs to save money when they have basically recovered from their illness. ${ }^{44} 67$ To solve this problem, a smooth medical insurance system should be established to enable reimbursement nationwide and guarantee the feasibility of referral. The proportion of reimbursement of medical insurance should be further increased, ${ }^{60}{ }^{61}$ especially for health services in CHSs, to appeal to more patients. Meanwhile, the downward referral system should be improved (such as by implementing a definite process and standards) alongside the medical insurance system to guarantee the implementation and completion of downward referral. ${ }^{68}$

It must be admitted that patients' willingness to be referred from hospitals to CHSs is the most important factor in the implementation of downward referral. Results indicate that a positive attitude towards the community first treatment system increased patients' willingness for downward referral. Supported by previous studies, patients supporting the community first treatment system were more willing to be referred to CHSs; ${ }^{24}{ }^{69}$ however, compared with the fact that $90 \%$ of patients are first treated by GPs in Britain, ${ }^{70} 71$ only a few patients in China want to be first treated in CHSs and accept downward referral. Studies also suggest that $70.33 \%$ of doctors in CHSs considered their limited medical technology the main obstacle to the community first treatment system, while $65.07 \%$ regarded the inconvenient downward referral service as the main problem. ${ }^{44}$ Therefore, to promote patients' willingness for downward referral, there is an urgent need to establish a new medical seeking pattern (preference for CHSs) and a better CHS. Changes could be made to change patients' attitudes towards CHSs, trust in CHSs and the quality of CHSs, such as strengthening social propaganda, ${ }^{31}$ promoting patients' understanding of the downward referral system, ${ }^{23}$ eliminating bias against
CHSs, defining and optimising a convenient downward referral process, increasing the number of GPs, providing GPs with more opportunities for further study, improving the cooperation network between hospitals and CHSs, formulating a unified referral process and standards, and clarifying explicit downward referral guidelines for different types of patients. ${ }^{21} 2272$

Finally, of the sociodemographic characteristics, only marital status affects patients' willingness for downward referral. Compared with single patients, those married were less willing to be referred from hospitals to CHSs. However, while marital status was an influencing factor in this study, other studies do not provide evidence of this result. This result may be attributed to economic factors. Married patients undertake fewer financial burdens; thus, they are more likely to refuse downward referral and stay in hospitals for further rehabilitation. However, to more explicitly interpret this result, further research must be conducted.

\section{Limitations}

There are some limitations to this study. First, concerning the complexity of the behaviours of doctors and patients, this study selected the most important factors influencing downward referral based on the literature and expert consultation. Some factors, such as the number of years doctors have worked in a hospital, type of disease, transportation, location of CHSs and provision of medicine in CHSs, will be introduced into the questionnaire for further study. Second, the present research focused on doctors and patients in hospitals. Doctors from different healthcare institutions and with different working experience, such as those who have worked in the CHS and now work in the hospital, and doctors who only work in CHSs, were not included. Third, since this study is set in an urban area, people from rural areas choose to go there for treatment as the perceived quality of care is better. However, whether there is a relation between geographical location and seriousness of diseases needs to be explored. Therefore, follow-up surveys on patients referred from hospitals to CHSs and seriousness of diseases of patients from different regions will be added, and the perception of doctors who worked in the CHS and now work in the hospital and those who only work in hospitals will be compared. We will also compare medical costs and healthcare quality, as well as explore the reasons, willingness, satisfaction and treatment effects before and after downward referral.

\section{CONCLUSION}

Doctors' willingness to make downward referrals is influenced by their level of education, attitude towards workload affected by downward referral, perception of health resources in hospitals and understanding of the downward referral process. Patients' willingness for downward referral is influenced by their marital status, economic 
factors and recognition of the community first treatment system. To promote the rate of downward referral, hospitals should encourage doctors to make appropriate downward referral decisions, and improve doctors' understanding of the shortage of health resources in hospitals, especially for those with a lower degree of education. Hospitals should change their attitudes towards downward referral, not for their own monetary profit, but to benefit the country and population. Optimising the downward referral process will alleviate the workload caused by downward referral, and thus increase doctors' willingness to make downward referrals. In addition, paying attention to the marital status of patients will help doctors encourage more patients to accept downward referral. Economic benefits from downward referral is important, especially the reimbursement of medical insurance and the standard reimbursement process. In addition, the implementation of the community first treatment system is important to downward referral, and more effort should be focused on this. In conclusion, changing the practices and attitudes of doctors and patients towards downward referral will ultimately increase their willingness to accept downward referrals.

Contributors This manuscript was jointly completed by WY, ML, XN, TD, FY, $\mathrm{JL}, \mathrm{ZD}$ and $\mathrm{LZ}$. WY, ML and XN contributed equally to this research. WY made substantial contributions to conception and design, analysis and interpretation of data, drafting the manuscript and revising it critically for important intellectual content. ML and XN made substantial contributions to conception and design, interpretation of data, and drafting the manuscript. TD, FY, JL and ZD were involved in data collection. LZ made substantial contributions to conception and design, and gave final approval of the version to be published.

Funding The project was supported by the National Natural Science Foundation of China (71233008, 71673291, 71303248, 91224005), Joint Research Project of Major Disease of Shanghai Health System (2013ZYJB0006) and the Major Project in the '12th Five-Year Plan' of the People's Liberation Army (AWS12J002).

Competing interests None declared.

Patient consent Obtained.

Ethics approval The study was approved by the Ethics Committee of Second Military Medical University.

Data sharing statement No additional data are available.

Open Access This is an Open Access article distributed in accordance with the Creative Commons Attribution Non Commercial (CC BY-NC 4.0) license, which permits others to distribute, remix, adapt, build upon this work noncommercially, and license their derivative works on different terms, provided the original work is properly cited and the use is non-commercial. See: http:// creativecommons.org/licenses/by-nc/4.0/

\section{REFERENCES}

1. Li ZQ, Lin F. The introduction of the first-treatment system at community abroad. Chin Health Econ 2006;25:76-7.

2. Jiang LP. Solve the medical problems should support community health service institutions. Hospital Newspaper. 2006.

3. Wan $\mathrm{BH}$, Liu $\mathrm{S}$, Feng $\mathrm{XL}$, et al. Analysis of existing problems and solutions of the implementation of two-way referral in Changchun. Med Soc 2007;20:31-3.

4. Liu L, Liu GW, Zhang XP, et al. Analysis of referral factors of outpatients. Chin Health Serv Manag 2008;25:400-2.
5. Chilingerian JA, Sherman HD. DEA and primary care physician report cards: deriving preferred practice cones from managed care service concepts and operating strategies. Ann Operations Res 1997;73:35-66.

6. Staat M. The efficiency of treatment strategies of general practitioners. Eur J Health Econ 2003;4:232-8.

7. Sørensen TH, Olsen KR, Gyrd-Hansen D. Differences in general practice initiated expenditures across Danish local health authorities: a multilevel analysis. Health Policy 2009;92:35-42.

8. Puig-Junoy J, Ortún V. Cost efficiency in primary care contracting: a stochastic frontier cost function approach. Health Econ 2004:13:1149-65

9. Thanassoulis E, Portela MCS, Graveney M. Estimating the scope for savings in referrals and drug prescription costs in the general practice units of a UK primary care trust. Eur $J$ Operational Res 2012;221:432-44.

10. Stainkey LA, Seidl IA, Johnson AJ, et al. The challenge of long waiting lists: how we implemented a GP referral system for non-urgent specialist' appointments at an Australian public hospital. BMC Health Serv Res 2010;10:303.

11. French JA, Stevenson $\mathrm{CH}$, Eglinton J, et al. Effect of information about waiting lists on referral patterns of general practitioners. Br J Gen Pract 1990;40:186-9.

12. Messina FC, McDaniel MA, Trammel AC, et al. Improving specialty care follow-up after an ED visit using a unique referral system. Am J Emerg Med 2013;31:1495-500.

13. McDonald K, Iredale R, Higgs G. Primary care referrals to a British regional cancer genetics service. J Clin Nurs 2008;17:3074-6.

14. Zuckerman KE, Perrin JM, Hobrecker K, et al. Barriers to specialty care and specialty referral completion in the community health center setting. J Pediatr 2013;162:409-14.e1.

15. Zuckerman KE, Nelson K, Bryant TK, et al. Specialty referral communication and completion in the community health center setting. Acad Pediatr 2011;11:288-96.

16. Shea D, Stuart B, Vasey J, et al. Medicare physician referral patterns. Health Serv Res 1999;34(1 Pt 2):331-48.

17. Bachman $\mathrm{KH}$, Freeborn DK. HMO physicians' use of referrals. Soc Sci Med 1999:48:547-57.

18. Walshe $\mathrm{C}$, Chew-Graham $\mathrm{C}$, Todd $\mathrm{C}$, et al. What influences referrals within community palliative care services? A qualitative case study. Soc Sci Med 2008;67:137-46.

19. Wang H, Feng ZC, Li P. Analysis of influencing factors of referral from hospital to community in the two-way referral system. Chin $J$ Hosp Adm 2012;28:268-70.

20. Jin L, Yan XJ, Li J, et al. Discussion on influencing factors of the two-way referral in urban health service system. Chin J Hosp Adm 2007;23:772-4.

21. Jiang $\mathrm{H}$. Break down the dilemma of referral from hospital to community. China Hosp CEO 2012;23:68-9.

22. Wang LN, Wang J. Discussion on division of outpatients referring from hospital to community. Chin Health Res 2006;9:212-14.

23. Liu B, Zhang L. Analysis of the current situation and influencing factors of the continuity of basic medical services in China. Chin Health Econ 2008;27:12-15.

24. Shan N, Li JL. Analysis of downward referral will of patients in a secondary hospital, Beijing. Med Soc 2014;27:27-9.

25. Gan XQ, Li QP, Li H. Influential factors to downward referral for residents in rural areas. Chin Gen Pract 2011;7:720-2.

26. Wu YY. The pilot of rehabilitation medical system met bottleneck and the medical insurance system remained to be improved. Decis Mak Hosp Leadersh 2012;12:21-3.

27. Hu SY. The two-way referral, health resource allocation and medical insurance design. China Soc Secur 2009;9:79-80.

28. Jin L, Yan XJ, Li J, et al. Discussion on influencing factors of the two-way referral from hospital to community in urban health service system. Chin J Hosp Adm 2007;23:772-4.

29. Gan XQ, Jia QP, Li H. Influential factors to downward referral for residents in rural areas. Chin Gen Pract 2011;7:720-2.

30. China NHaFPCotPsRo. Chinese Health Statistical Year Book 2012. Chinese Peking Union Medical College Press, 2012.

31. Xu CE, Quan SC, Zhou XC, et al. Quantitative analysis of influencing factors of referral from hospital to community. Chin Health Serv Manag 2009;6:373-5.

32. Zhou LN, Tong ZL. Analysis on the difficulty of general hospital referral down. Med Philos 2014;1:68-9.

33. Baptist AP, Baldwin JL. Physician attitudes, opinions, and referra patterns: comparisons of those who have and have not taken an allergy/immunology rotation. Ann Allergy Asthma Immunol 2004;93:227-31. 
34. Iqbal CW, Kumar S, lqbal AD, et al. Perspectives on pediatric bariatric surgery: identifying barriers to referral. Surg Obes Relat Dis 2009;5:88-93

35. Ma X, Li NX, Ren XH, et al. Investigation on the KAP of medical staff in community about two-way referral. Modern Prev Med 2005;32:543-5.

36. Wong LY, Toh MPHS, Kong KH. Barriers to patient referral for complementary and alternative medicines and its implications on interventions. Complement Ther Med 2010;18:135-42.

37. Li DX, Du XP, Li F. Management and influential factors of the two-way referral: from the perspective of patients and doctors. Chin General Pract 2013;16:3590-3.

38. Pourhabib S, Chessex C, Murray J, et al. Elements of patienthealth-care provider communication related to cardiovascular rehabilitation referral. J Health Psychol 2016;21:468-82.

39. Blank L, Baird W, Reuber M. Patient perceptions of the referral of older adults to an epilepsy clinic: Do patients and professionals agree who should be referred to a specialist? Epilepsy Behav 2014;34:120-3.

40. Carlé A, Laurberg P, Pedersen IB, et al. Mainly the younger hypothyroid patients are referred to hospital-evidence for referral bias. J Clin Epidemiol 2009;62:446-51.

41. Paltiel O, Ronen I, Polliack A, et al. Two-way referral bias: evidence from a clinical audit of lymphoma in a teaching hospital. $J$ Clin Epidemiol 1998;51:93-8.

42. Ali A, Lahiry S, Khan AA, et al. A downward health care referral system in Bangladesh through diabetic association branches. Diab Res Clin Pract 2000;50:407.

43. Tan WY. Response scale for the disability module of WHOQOL5-point or 3-point? Sun Yat-Sen University, 2010.

44. Zhang YL, Wang L, Xu C, et al. Influential factors on the practice of "dual referral system" in Chaoyang District of Beijing. Chin Gen Pract 2010;13:3507-9.

45. Wu L, Wang Y, Peng X, et al. Development of a medical academic degree system in China. Med Educ Online 2014;19:23141.

46. Shen QH, Cao YN, Zhang YC, et al. The limitations of Chinese physicians' title system and its institutional design. Med Soc 2015;28:43-51.

47. Zhou YJ, Peng XM, Wang W, et al. The present situation and main problems of the two-way referral system in Xixiang, Shenzhen. Chin Prim Health Care 2007;21:26-9.

48. Dahhan A, Maddox WR, Krothapalli S, et al. Education of physician and implementation of a formal referral system can improve cardiac rehabilitation referral and participation rates after percutaneous coronary intervention. Heart Lung Circ 2015;24:806-16.

49. Gao Z, Li Q, Li B. Discussion of two-way referral flow and its social support system. Med Soc 2009;22:25-6.

50. Feng $\mathrm{Y}$, Zhang J. A review on two-way referral of urban community health service in China. Health Econ Res 2006;11:44-5.

51. Zhou B, Shi G, Li J, et al. Practice on the dual referral process based on the case of medical association. Chin Hosp 2015;19: 25-6.

52. He Z, Huang J, Chen X, et al. Designing a two-way referral process by taking service desk as a bond. Chin Rural Health Serv Adm 2009;29:117-19.
53. Mai SP, Zhang J, Fu XT, et al. Factor analysis on the satisfaction of personnel with community health centers in Shanghai. Chin Gen Pract 2013;16:3301-3.

54. Zhang SL. Reasons and solutions to the situation of visiting tertiary hospitals when just having a minor disease. Theory Res 2013;32:98-9.

55. Bao Y. Develop strongpoint and carry out "two-way referral" in deed. Hosp Dir Forum 2009;5:30.

56. Wang QL. Influencing factors and measures of the establishment of the two-way referral system between general hospitals and community health service institutions. Chin Prim Health Care 2004;18:13-14

57. Liu M, Chen JH, Peng XM. Significance and proposal of two-way referral between hospital and community health service institution. Chin Gen Pract 2004;7:38-9.

58. Liu B, Zhang L. The present situation and influencing factors of continuous service in PHC. Chinese Health Economics. 2006;27:12-15.

59. Du J, Lu X, Wang Y, et al. Mutual referral: a survey of GPs in Beijing. Fam Pract 2012;29:441-7.

60. Shao S, Zhao F, Wang J, et al. The ecology of medical care in Beijing. PLOS ONE 2013;8:e82446.

61. Zhao Y, Cui S, Yang J, et al. Basic public health services delivered in an urban community: a qualitative study. Public Health 2011;125:37-45.

62. Wang J, Chen FY, Xu JP, et al. Analysis of general practitioner system in the UK and its enlightenment. Chin J Med Educ Res 2014;13:109-12.

63. Wang W. West meets east: Chinese and US doctors addressing the medical ecology and disease management from both countries perspectives. Fam Med Community Health 2015;3:1-3.

64. Bittner V, Sanderson B, Breland J, et al. Referral patterns to a University-based cardiac rehabilitation program. Am J Cardiol 1999;83:252-5, A5.

65. Ling RE, Liu F, Lu XQ, et al. Emerging issues in public health: a perspective on China's healthcare system. Public Health 2011;125:9-14.

66. Peng $X$, Song S, Sullivan $S$, et al. Ageing, the urban-rural gap and disability trends: 19 years of experience in China-1987 to 2006 . PLOS ONE 2010;5:e12129.

67. Xia XL, Ma LN, Jia LG, et al. A survey on up-down transferring of community health service in Huangshi City. Chin J Soc Med 2008;25:111-13.

68. Zhou SW, Yu XQ, Huang $X$, et al. The influencing factors of satisfaction on the two-way referral service among residents in the town of Sanxiang in the city of Zhongshan. Med Innov China 2014;11:106-8.

69. Chen C, Zhang XP, Zhou ZM. Analysis of the dual referral will of patients. Chin Health Econ 2008;27:43-4.

70. DoH. The new NHS: modern, dependable. HMSO London, 1997.

71. Lei XS. The occupation training and continuing education of GP in the United Kingdom. Chin Gen Pract 2006;9:902.

72. Al-Namash $\mathrm{H}$, Al-Najiar A, Kandary WA, et al. Factors affecting the referral of primary health care doctors toward bariatric surgery in morbid obesity. Alexandria J Med 2011;47:73-8. 